\title{
Comment on "Comparison of tru-cut biopsy and fine-needle aspiration cytology in an experimental alcoholic liver disease model"
}

Sümeyye Ekmekci'

1. Health Sciences University Tepecik Training and Research Hospital, Department of Pathology, Izmir, Turkey.

Alcohol abuse is a serious cause of morbidity and mortality worldwide ${ }^{1}$. Fatty liver and/or inflammation is observed on the basis of alcoholic liver disease which is one of the conditions caused by alcohol use. In chronic alcohol consumption, steatosis or steatohepatitis can be observed and, in 10\% of cases, cirrhosis development is also found ${ }^{2}$. It has been suggested that gender differences, genetic and environmental factors, and personal differences in nutrition and alcohol metabolism play a role in the origin of this different course ${ }^{3}$.

While diagnostic imaging methods are more helpful for the evaluation of fatty changes, histopathological examinations are more prominent to determine the degree of inflammation. In histopathological examinations, many pathological processes such as the degree of fatty changes, the location of inflammation and the type of inflammatory cells, the degree and extent of fibrosis, the condition of the biliary tract, and the presence of different deposits can be shown ${ }^{4}$. However, possible complications that may be encountered with histopathological tissue extraction methods such as excisional or incisional biopsy from the liver may have serious consequences in some cases. For this reason, cytopathological examination, which is one of the less invasive methods, comes to the forefront. However, studies on the subject are limited.

In alcoholic liver disease, the histopathological evaluation must be compared with the cytopathological examination, which has fewer complications ${ }^{5}$. Subsequently, if the results of cytopathological studies give similar results to the histopathological examination, it is recommended to increase its use in daily practice. In addition, it is thought that due to the lower risk of complications, repeatability of cytopathological examination may be higher, and it will contribute to the understanding of the pathophysiology of different courses in different cases.

\section{REFERENCES}

1. GBD 2016 Alcohol Collaborators. Alcohol use and burden for 195 countries and territories, 1990-2016: a systematic analysis for the Global Burden of Disease Study 2016. Lancet. 2018;392(10152):1015-35.

2. Sanyal AJ, Boyer TD, Lindor KD, Terrault NA. Zakim and Boyer's hepatology: a textbook of liver disease. $7^{\text {th }}$ ed. Philadelphia: Elsevier; 2017.

3. Kourkoumpetis T, Sood G. Pathogenesis of alcoholic liver disease: an update. Clin Liver Dis. 2019;23(1):71-80.

4. Torruellas C, French SW, Medici V. Diagnosis of alcoholic liver disease. World | Gastroenterol. 2014;20(33):11684-99.

5. Adali Y, Eroğlu HA, Makav M, Karayol SS, Güvendi GF, Gok M. Comparison of tru-cut biopsy and fine needle aspiration cytology in an experimental alcoholic liver disease model. Rev Assoc Med Bras. 2020; 66(8):1030-1035. 